Supporting Information

\title{
Functionalized Amphiphilic Diblock Fullerene Derivatives as Cathode Buffer Layer for Efficient Inverted Organic Solar Cells
}

\author{
Jikang Liu, Yao Wang, Pengfei Jiang, Guoli Tu* \\ Wuhan National Laboratory for Optoelectronics, Huazhong University of Science and \\ Technology, Wuhan, Hubei, 430074, PR China \\ E-mail: tgl@hust.edu.cn
}




\section{RESULT AND DISCUSSION}

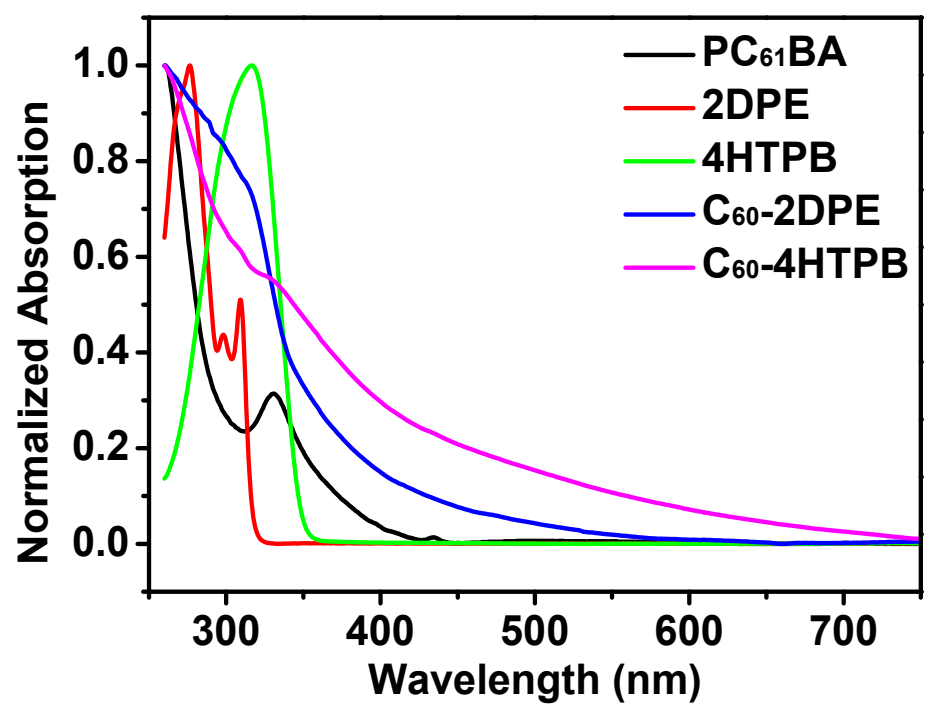

Figure S1. UV-vis absorption spectrum of the $\mathrm{PC}_{61} \mathrm{BA}, 2 \mathrm{DPE}, 4 \mathrm{HTPB}, \mathrm{C}_{60}-2 \mathrm{DPE}$ and $\mathrm{C}_{60}-4 \mathrm{HTPB}$.

\section{2. ${ }^{1}$ H NMR SPECTRUMS}

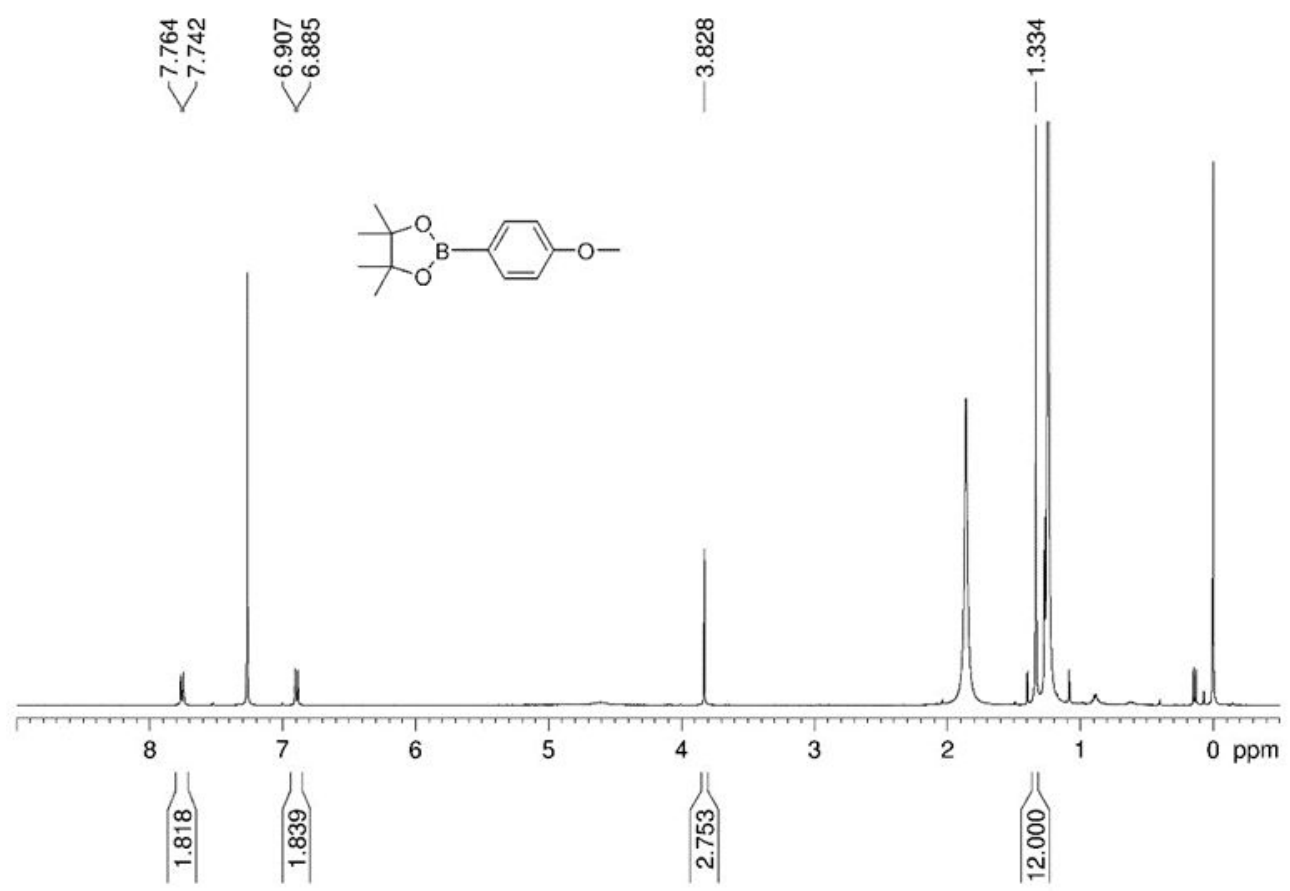

Figure S2. ${ }^{1} \mathrm{H}$ NMR spectrums of 2-(4-methoxyphenyl)-4,4,5,5-tetramethyl-1,3,2dioxaborolane (a) 


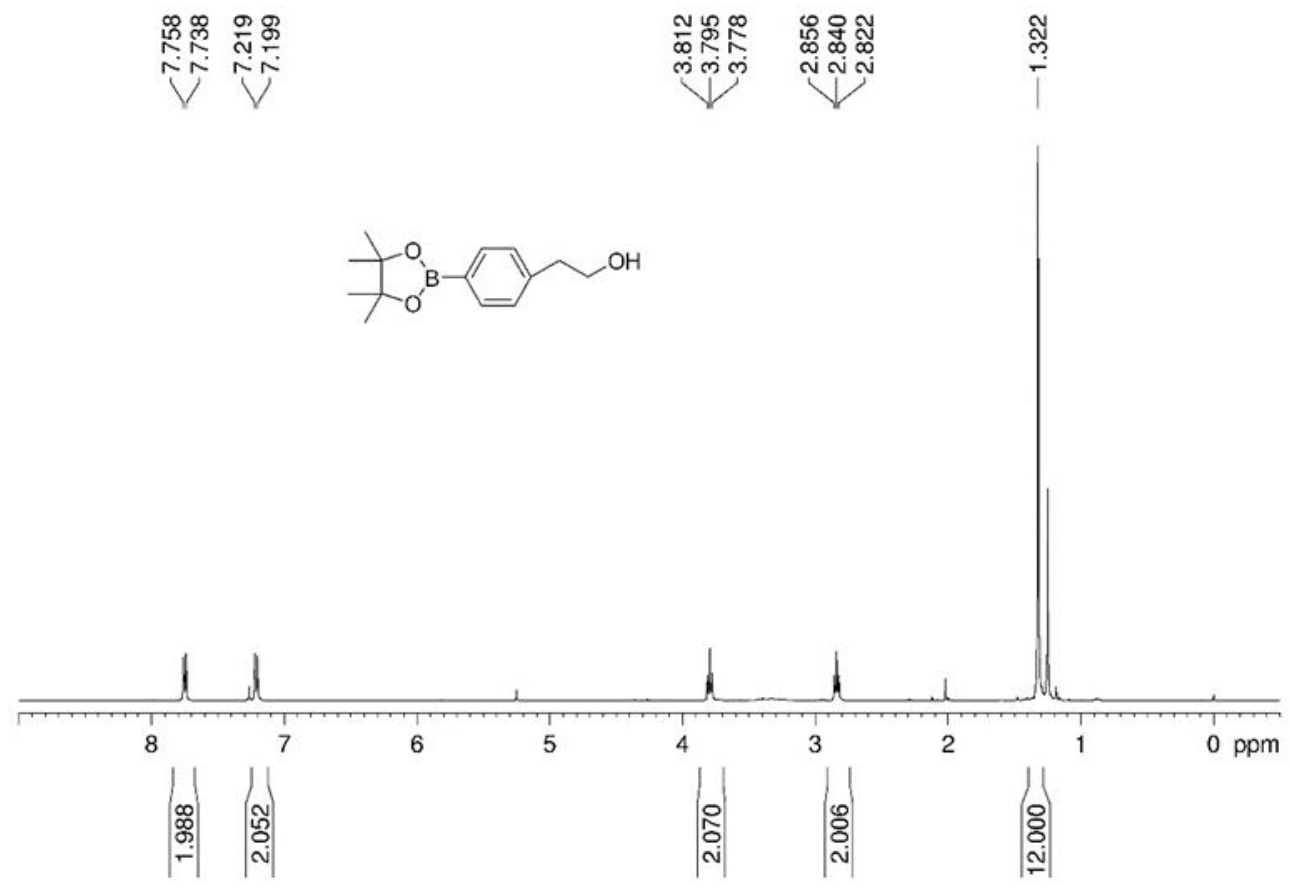

Figure S3. ${ }^{1} \mathrm{H}$ NMR spectrums of 2-(4-(4,4,5,5-tetramethyl-1,3,2-dioxaborolan2-yl)-phenyl)-ethan-1-ol (b)

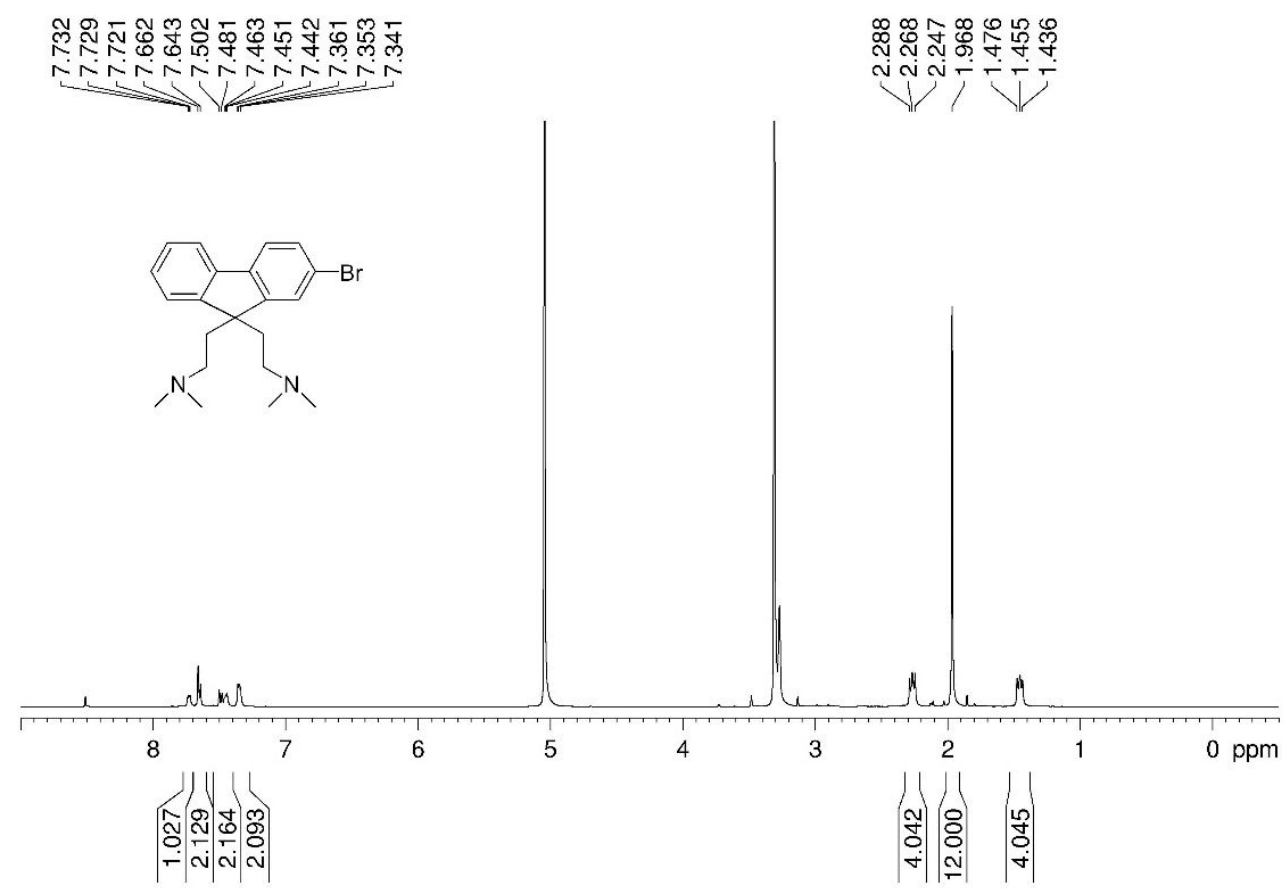

Figure S4. ${ }^{1} \mathrm{H}$ NMR spectrums of 2,2'-(2-bromo-9H-fluorene-9,9-diyl)-bis-(N,Ndimethylethan-1-amine) (c) 


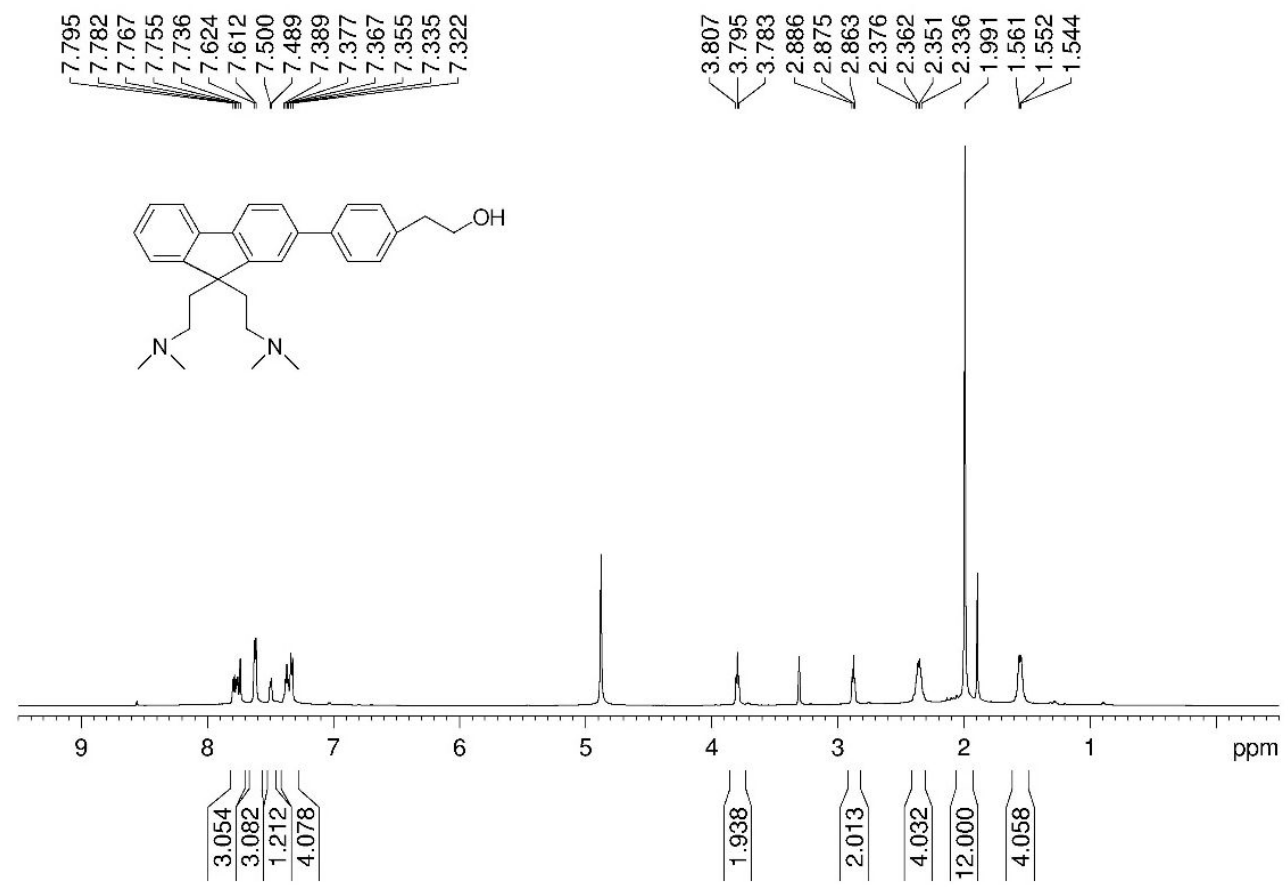

Figure S5. ${ }^{1} \mathrm{H}$ NMR spectrums of 2-(4-(9,9-bis-(2-(dimethylamino)-ethyl)-9Hfluoren-2-yl)-phenyl)-ethan-1-ol (2DPE)

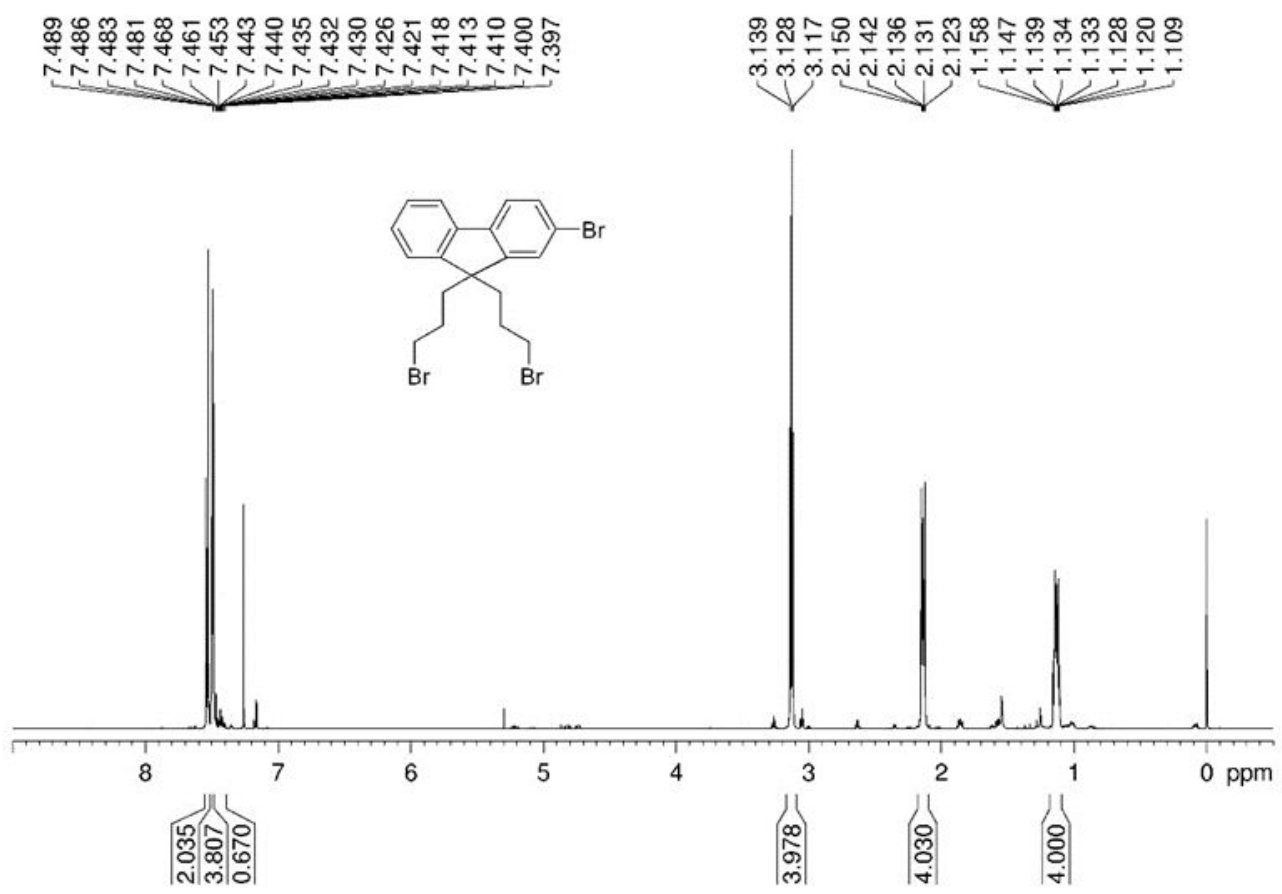

Figure S6. ${ }^{1} \mathrm{H}$ NMR spectrums of 2-bromo-9,9-bis-(3-bromopropyl)-9H-fluorene (d) 


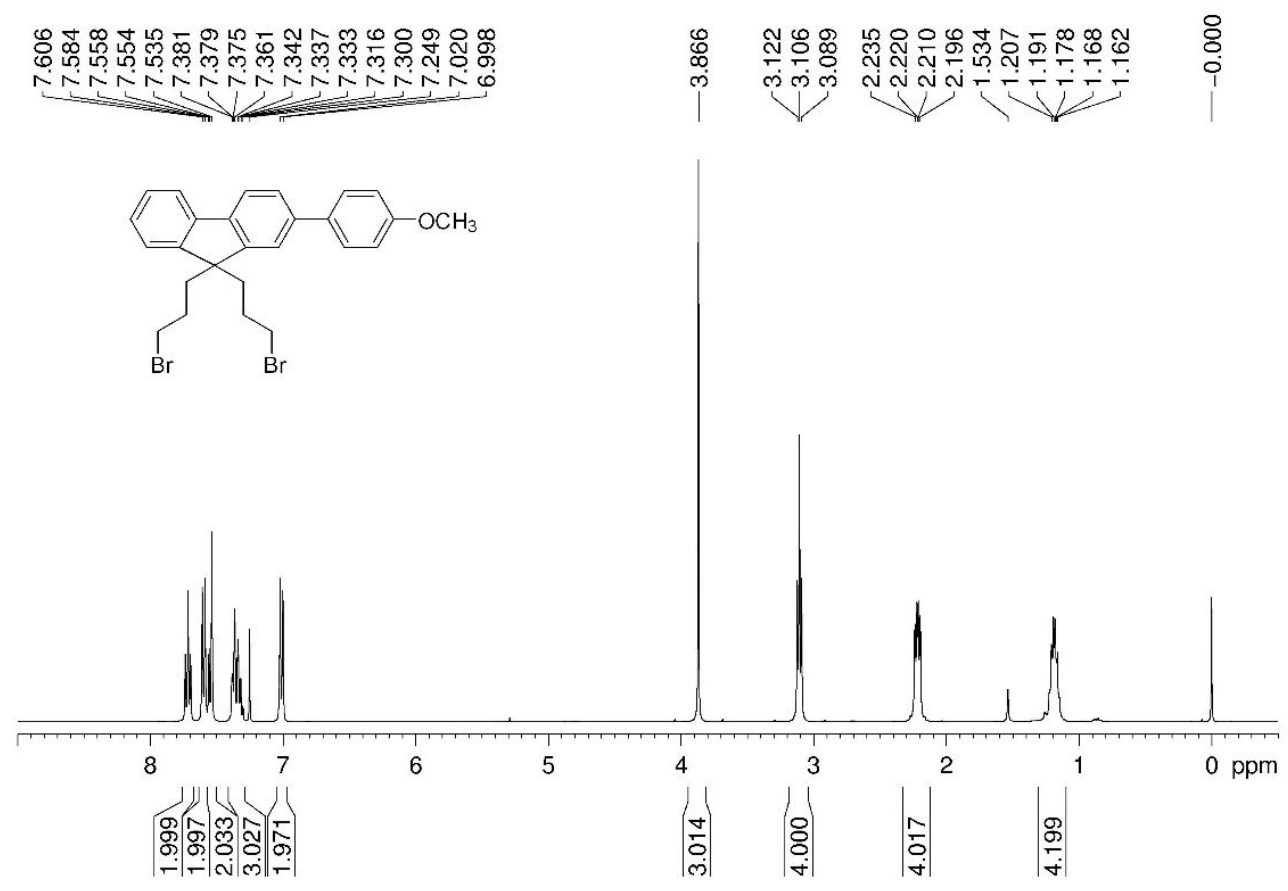

Figure S7. ${ }^{1} \mathrm{H}$ NMR spectrums of 9,9-bis-(3-bromopropyl)-2-(4-methoxyphenyl)9H-fluorene (e)

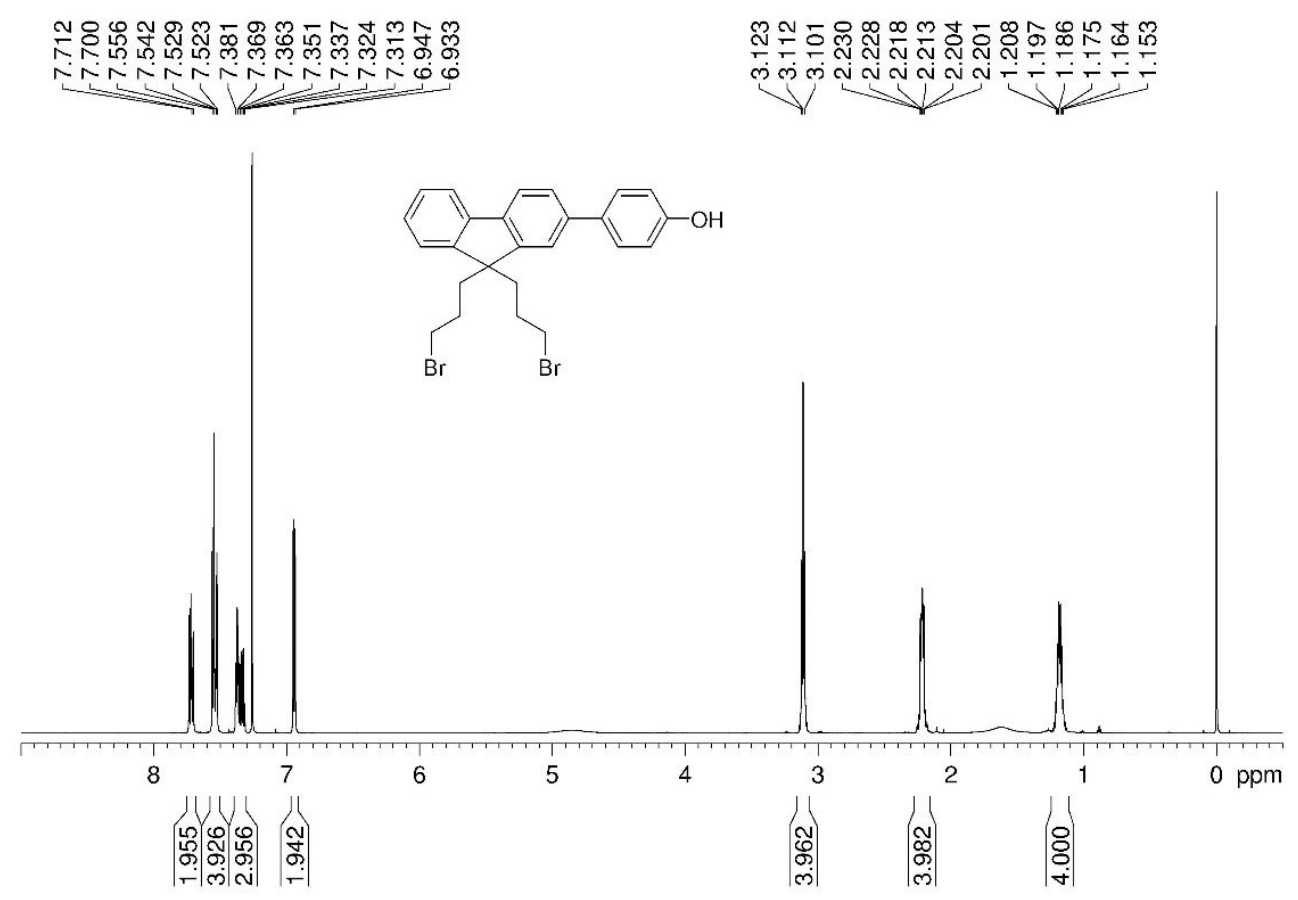

Figure S8. ${ }^{1} \mathrm{H}$ NMR spectrums of 4-(9,9-bis(3-bromopropyl)-9H-fluoren-2-yl)-phenol (f) 


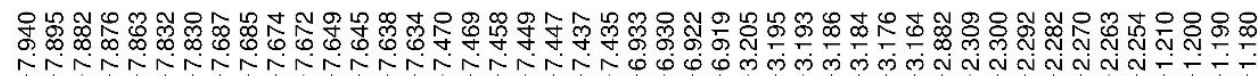

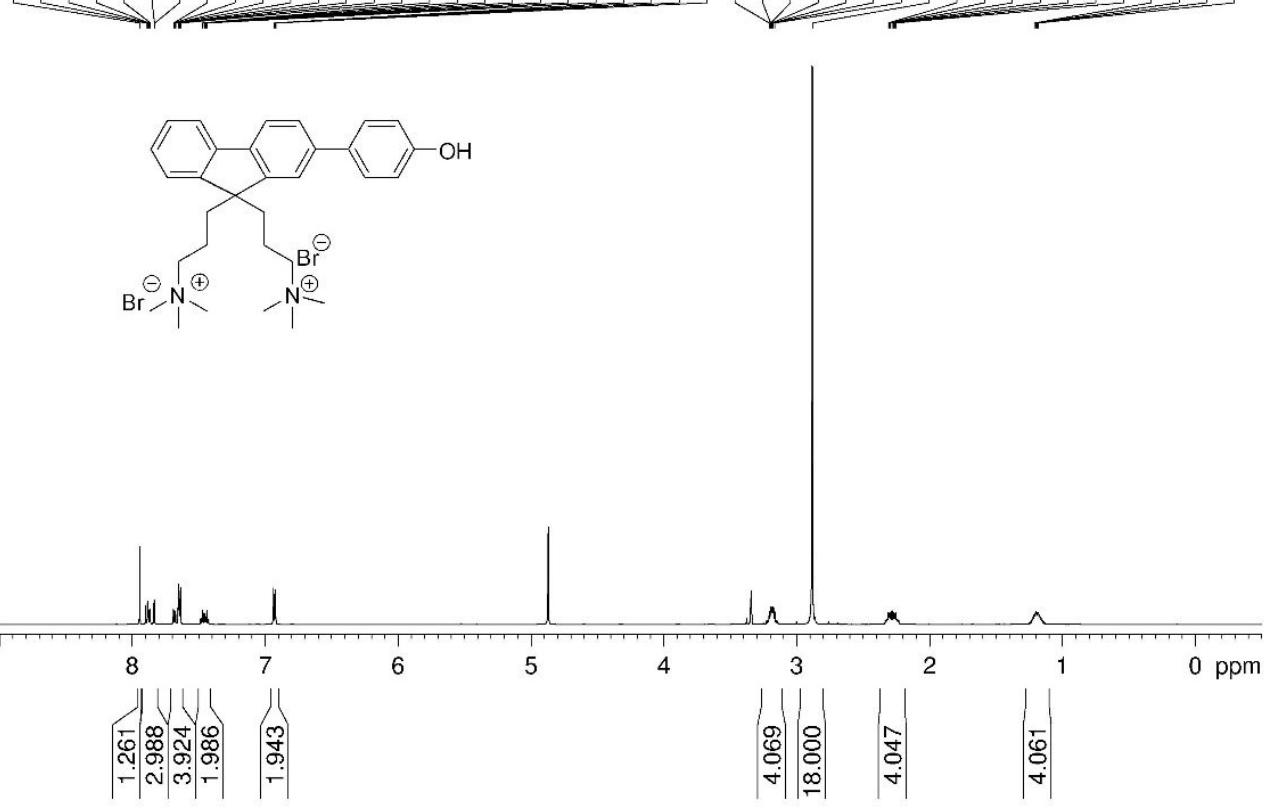

Figure S9. 'H NMR spectrums of 3,3'-(2-(4-hydroxyphenyl)-9H-fluorene-9,9-diyl)bis-(N,N,N-trimethylpropan-1-aminium) -bromide (4HTPB)

\section{THREE-DIMENSIONAL (3D) ARCHITECTURE}

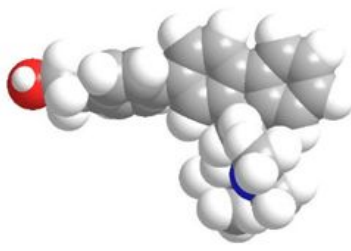

2DPE

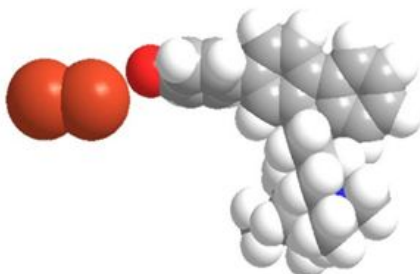

4HTPB

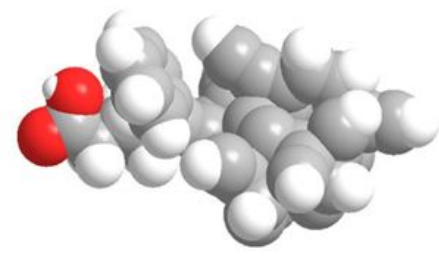

PC 61 BA
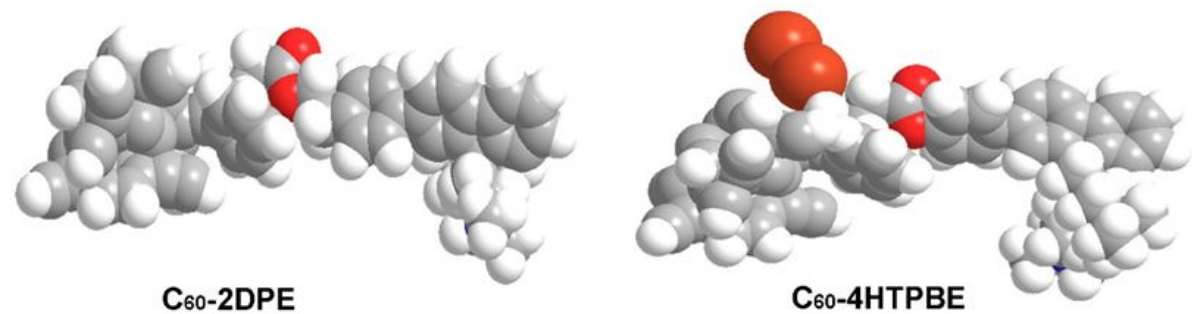

Figure S10. 3D architecture of $\mathrm{PC}_{61} \mathrm{BA}, 2 \mathrm{FPE}, 4 \mathrm{HTPB}, \mathrm{C}_{60}-2 \mathrm{DPE}$ and $\mathrm{C}_{60}-4 \mathrm{HTPB}$. 